\title{
Epistemic injustice in mathematics education
}

\author{
Fenner Stanley Tanswell ${ }^{1}\left[\right.$ Colin Jakob Rittberg $^{1}$
}

Accepted: 4 June 2020 / Published online: 18 June 2020

(c) The Author(s) 2020

\begin{abstract}
Equity and ethics in the learning of mathematics is a major topic for mathematics education research. The study of ethics and injustice in relation to epistemic pursuits, such as mathematics, is receiving a great deal of interest within contemporary philosophy. We propose a bridging project between these two disciplines, importing key ideas of "epistemic injustice" and "ethical orders" from philosophy into mathematics education to address questions of ethics, equity, values and norms. We build on Dawkins and Weber's (Educ Stud Math 95:123-142, 2017) "apprenticeship model" of learning proofs and proving, which says that mathematics education should reflect the practices of research mathematicians. Focusing on the norms and values implicit in mathematical proving, we argue that deploying this model unreflectively can lead to "epistemic injustices" in which learners are disadvantaged based on their cultural or class background. We propose thinking about the problem in terms of Max Weber's "ethical orders", and the clash that arises between the ethical orders of mathematics and the existing ethical orders of the learners and teachers of mathematics. Weber's lesson is that sometimes these clashes have no overarching resolution, and so the mathematics classroom may also have to settle for tailored pragmatic measures to combat individual cases of epistemic injustice.
\end{abstract}

\section{Introduction}

Mathematical practices are governed by norms and values. Dawkins and Weber (2017) focus on mathematical proving practices and individuate a list of principles which, as they convincingly argue, reflects some of the values of mathematical proving practices and the norms in place to uphold these values. According to their apprenticeship model of mathematics education, classroom mathematics should reflect professional mathematical practices, i.e. learners should be enculturated into these research-level norms and values of proving. This leaves the (cultural, social, economic, gender, racial, etc.) background of the learners unaccounted for. This is a research gap with, as we argue, ethical implications. We show that there are ethical reasons to negotiate and adjust the norms and values of mathematics during teaching to fit with the values upheld by the learners in the classroom. The aim of this paper is to provide a philosophical framework

Fenner Stanley Tanswell

F.Tanswell@lboro.ac.uk

Colin Jakob Rittberg

C.J.Rittberg@lboro.ac.uk

1 Loughborough University, Loughborough, UK which helps to understand the ethics of this research gap and provides a first step towards traversing it.

Methodologically, we are approaching mathematics education as philosophers of mathematics, with primary interests in mathematical practices, proofs, and the ethics and epistemology of mathematics. The aim of this paper is to provide a philosophical framework for questions about the ethics of teaching proofs in the classroom. Many of the concepts used in the mathematics education literature, such as norms, values, justice and skills, have long philosophical histories, and interdisciplinary approaches promise valuable insights. We argue that the concept of epistemic injustice (and its associated philosophical framework) picks out an important kind of injustice that can appear in mathematics education. We also aim to provide the philosophical ideas with a real-world testing ground in mathematics education, akin to Kotzee's (2017) examinations of epistemic injustice in education settings more generally.

In Sect. 2 we introduce epistemic injustice as a philosophical framework that helps to reveal the ethical imperative to traverse the above-mentioned research gap of the apprenticeship model. We elaborate the framework by application throughout the paper.

In Sect. 3 we present Dawkins and Weber's (2017) apprenticeship model in more detail. We agree with the 
sentiment the model expresses but see the need to refine it to account for the ethical challenges it faces.

In Sect. 4 we identify the research gap in the apprenticeship model that is the focus of this paper. We discuss a variety of examples from mathematics education studies that reveal how the norms and values of mathematics can conflict with the norms and values of learners. We focus in particular on the cultural and class backgrounds of learners, leaving aside concerns such as race, gender, or economic considerations due to lack of space. Our considerations reveal that the apprenticeship model does not sufficiently account for the background of learners. We employ the epistemic injustice framework to reveal the ethical imperative to traverse this gap.

In Sect. 5 we introduce another philosophical framework, ethical orders, which will help to traverse the research gap. We borrow the concept from Max Weber $(1917 ; 1919)$ and Larvor (2018).

In Sect. 6 we argue that in the classroom the ethical order of mathematics ought to be mediated with the demands of the ethical orders learners are already committed to in order to avoid epistemic injustice.

In Sect. 7 we suggest, with Larvor (2018), that conflicts between ethical orders may only allow for pragmatic caseby-case but not for theoretical general solutions. That is to say that the apprenticeship model of mathematics education expresses a desirable sentiment, "let the teaching of mathematics reflect actual mathematical practices", but for ethical reasons this sentiment requires negotiation and adjustment to the particulars of each classroom context.

The three main research questions we will address in this paper are:

1. What are the ethical dimensions of the apprenticeship model of mathematics education?

2. How does epistemic injustice manifest itself in this setting?

3. Can the notion of ethical orders provide a fruitful framework for understanding the ethical dimensions of the apprenticeship model?

\section{Epistemic injustice}

The purpose of this section is to introduce epistemic injustice as a philosophical framework. We employ this framework in Sect. 4 to reveal the ethical imperative to traverse the research gap in the apprenticeship model. In Sects. 6 and 7 we discuss means how such epistemic injustice in the mathematics classroom may be avoided.

Much of the production and handling of human knowledge is done in social contexts: teachers explain to their students, research teams work together, and friends tell each other secrets. These are epistemic actions because they contribute to the development and transmission of knowledge, but they are also human interactions which invite ethical reflection: teachers can be virtuously fair towards their students, research teams may be biased against certain races or genders, and friends may betray each other. There are points of connection between epistemology and ethics.

Injustices belong to the domain of ethics but because ethics and epistemology connect there are some injustices that impact epistemological endeavours; a xenophobic teacher might disadvantage some of her students in a way that systematically harms them as epistemic agents. Injustices that affect humans specifically in their roles as epistemic agents are called epistemic injustices.

Epistemic injustices have received considerable attention from philosophers in recent years (Fricker 2007; Medina 2013; Kidd et al. 2017). Pohlhaus (2017, p. 13) identifies three senses in which epistemic injustice has been discussed in the literature:

1. injustices suffered by a knower, such as when her testimony is not given due credit.

2. injustices perpetrated by a knower, such as when a knower stymies inquiry.

3. injustices that are caused by an epistemic institution in its capacity as an epistemic institution, such as academic curricula which systematically ignore or distort intellectual traditions.

Pohlhaus stresses that her considerations should not be read as a definition of the term because any definition of epistemic injustice might foreclose enquiry into other forms of injustices that may manifest in epistemological activity, especially enquiry "along trajectories that may be more readily noticed by those who are differently located than I am" (ibid., p. 14). We agree with this sentiment. Our aim in this section is to develop epistemic injustice as a conceptual framework to get at relevant issues at the points of connection between ethics and epistemology; we do not aim to define the concept.

The seminal book that started a sustained academic investigation of epistemic injustice is Fricker (2007). She makes explicit the connections of epistemic injustice and power relations; the subtitle of her book is "Power \& the Ethics of Knowing". According to Fricker, the philosophical literature on the ethics and politics of epistemic practices in terms of power is prone to treating all epistemic actions in terms of power. She argues that such a reductionism obscures the distinction between "what we have reason to think and what mere relations of power are doing to our thinking" (p. 3). This reductionism pre-empts questions about justice in epistemic practices, so Fricker argues; see also (Fricker 2007). To counteract this Fricker proposes "epistemic injustice" as 
a conceptual framework which is entangled with problems of power and social relations without suggesting that all injustices in epistemic action arise solely out of power and social relations. The success of this approach is evidenced in the growing body of literature on the topic (cf. above). In this paper we take these insights seriously and frame our discussion of the ethics of the apprenticeship model in terms of epistemic injustice rather than power relations.

Fricker (2007) focuses on testimonial injustices and hermeneutical injustices. Testimonial injustices manifest when "a speaker receives an unfair deficit of credibility from a hearer owing to prejudice on the hearer's part" (Fricker 2007 , p. 9), such as a doctor who does not take seriously a female patient's medical complaints due to the prejudiced belief that women whinge more. ${ }^{1}$ Hermeneutical injustice manifests when "someone has a significant area of their social experience obscured from understanding owing to prejudicial flaws in shared resources for social interpretation." (p. 148). Fricker gives sexual harassment as an example of such a resource which was lacking in the 1950s. Women who suffered from sexual harassment found, according to Fricker, their social experiences obscured by a lack of conceptual resources.

Hookway (2010) points out that Fricker concentrates on an informational perspective of epistemic injustice on which we evaluate epistemic agents in terms of their ability to give and receive information. He extends Fricker's framework by including a participant perspective in which an epistemic agent may suffer from epistemic injustice if she is unjustly blocked from participating in an epistemic practice. For example, in US schools black students are often discouraged from participating in high-level mathematics courses even if their achievements are similar to those of their high-level courses attending white peers (Kelly 2009).

Fricker's informational perspective and Hookway's participant perspective align with Pohlhaus' first sense of epistemic injustice: injustices suffered by an epistemic agent. However, for Fricker and Hookway the perpetrator of the injustice is also an epistemic agent, which aligns with Pohlhaus' second sense. Furthermore, in Rittberg, Tanswell and Van Bendegem (2018) we discuss how one mathematician may have suffered from Hookway's participatory kind of epistemic injustice. The sources for this injustice are the current social dynamics and publication practices in professional mathematics, i.e. mathematics as an epistemic institution causes the injustice here-which is Pohlhaus' third sense. Pohlhaus' three senses are thus porous and do not provide clear dividing lines between different types of epistemic

\footnotetext{
1 A deplorable state of affairs that occurs more often than can comfortably be admitted (Carel and Kidd 2014).
}

injustice. Rather, they encourage multi-dimensional thinking about the issue.

In this paper we are primarily concerned with the kind of epistemic injustice mathematics as an academic institution can cause to individual knowers. That is, this paper is written primarily from the perspective of Pohlhaus' third sense. Yet these senses are porous and so we will switch perspective (from those perpetrating the injustice to those suffering from it or vice versa) without much ado.

\section{The apprenticeship model of mathematics education}

In this section we introduce the apprenticeship model of teaching mathematics as presented by Dawkins and Weber (2017). According to this model, classroom mathematics should reflect professional mathematical practices. Dawkins and Weber focus on proving practices. Our focus is on the norms and values associated to the context-independence of proofs. In the next section we show how these demands leave open a research gap: relevant aspects of students' backgrounds are not accounted for in the apprenticeship model. In Sects. 6 and 7 we propose ways to traverse this gap.

Dawkins and Weber (2017) examine when and how we should be teaching proofs and proving in mathematics education. They argue that one of the key difficulties students have with learning to prove statements in a way akin to research mathematicians, what they call the "apprenticeship model", is that the students are not familiar with the underlying values exemplified in proofs and thus struggle to adhere to the norms which uphold these values. They understand these terms thus:

Values: are taken to "represent a community's shared orientations and goals that underlie shared activity" (ibid., p. 125). These may be implicit and need not be constantly set out and secured by practitioners.

Norms: are roughly characterised as "expectations on practice accepted by the scientific community to uphold a value" (ibid., p. 126). Norms are associated with given values as ways of securing those values in practice. They are common standards and expectations for how members of the practice should act but can be breached in certain contexts.

Throughout this paper we follow Dawkins and Weber's conceptualisation of these terms.

Dawkins and Weber identify four values and various norms upholding these values of the proving practices of research mathematicians. Their four proof-focused values are (ibid., p. 128):

1. Mathematical knowledge is justified by a priori arguments. 
2. Mathematical knowledge and justifications should be a-contextual and specifically be independent of time and author.

3. Mathematicians desire to increase their understanding of mathematics.

4. Mathematicians desire a set of consistent proof standards.

Dawkins and Weber argue that these values are upheld by various associated norms. For example, the first value is upheld by norms insisting that proofs should work with stipulated definitions, be deductive, and must not admit rebuttals. These are thus explicitly norms about justification rather than discovery, but values and norms concerning discovery could also be set out in a similar manner.

In this paper we focus on Dawkins and Weber's second value: that mathematical justifications should be acontextual and be independent of time and author. The idea is that proofs should be "autonomous" so that they can be judged independently of the context they are found in. We note that it is not easy to spell out what "autonomy" means without reference to some elements of the context. For example, Easwaran's (2009) similar notion of transferability, the property of proofs that the proof steps alone are sufficient to convince the target audience, is still defined by Easwaran in terms of a community of experts and what would convince them.

Dawkins and Weber (2017) identify two norms that uphold the value of acontextual proofs:

- Mathematical proof is written without reference to author or reader's agency. (p. 129)

- A proof is an autonomous object, not a description of a problem-solving process. (p. 130)

The two norms implement the values of autonomous proofs and acontextual mathematics as the idea that a proof should be written with the intention to conceal its origin, context and discovery. ${ }^{2}$ Indeed, they quote Davis and Hersh (1981) on the "ideal mathematician" for whom "writing follows an unbreakable convention: to conceal any sign that the author or the reader is a human being" (p. 36). ${ }^{3}$

We argue that enforcing the acontextuality of proofs in the classroom introduces a research gap into the apprenticeship model because it negates the context of the learners' background. Dawkins and Weber know this. They argue that it can be difficult for learners to adapt to the norms and

\footnotetext{
2 This is contrary to the suggestion from the dialectical approach that the contexts of discovery and justification cannot and should not be so distinguished. See (Kneebone 1957; Lakatos 1976; Larvor 2001; Tanswell 2018).

${ }^{3}$ Sørensen et al. (2019) read (Davis \& Hersh 1981) instead as supporting the context-dependence of proofs.
}

to internalise the values they have identified because learners are not acontextual. We argue this is more than a mere difficulty for learners. We make the case that ignoring the background of learners is a source of epistemic injustice in the classroom by drawing on two insights. We briefly present them here. The empirical evidence for our claims is then delivered in the next section.

The first insight is concerned with the language used in proofs. Mathematical proofs are written in a peculiar form, involving, for example, the interweaving of symbols and words, avoiding the first-person "I", the unusual "Let $n$ be a number" style constructions, specialised use of imperatives and instructions, and being devoid of many features of natural language. ${ }^{4}$ This has the effect of elevating the regimented mathematical language that has grown up over the centuries to the level of being the sole vessel of objective mathematics. Indeed, mathematics is frequently spoken of as being its own language, as in Pimm (1987) and many others. This language only seems impartial from within mathematics. Once we realise that learners do not come from uniform linguistic backgrounds it quickly becomes apparent that the allegedly impartial language of mathematics is easier to access for some students than others. In the next section we will discuss cases where this has been shown to systematically disadvantage learners.

The second insight is the clash between the value of impersonal writing in mathematics, and the phenomenology of mathematical activity. A proof in research mathematics will usually obscure whether it is written by one person or by (say) twenty people, and is intended to do so in order to be autonomous and transferable as discussed above. Nonetheless, for many learners it may be that collaboration, peer-guidance, and collective problem-solving are the usual approach, both in the educational setting and in their dayto-day lives. Learners can struggle with the apparent need to turn mathematics into the solitary activity suggested by current standards of proof-writing.

\section{Identifying the research gap: two case studies}

In this section, we consider selections from the work in Mathematics Education on equity with a special focus on the teaching of proofs and proving in education. We present work on culture and class in education research, but note that similar research exists about other characteristics such as gender, race, or disability (Treisman 1992; Seceda et al. 1995; Wood 2013; Battey and Leyva 2016). Common across these examples are issues of value, identity and language

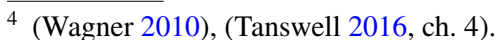


which stand as an extra barrier to participation in mathematics for some students that reinforce existing privilege. Daily mismatches in epistemic commitments between students and teachers can cumulatively lead to serious epistemic injustices. There is a tension between the norms and values teachers must uphold as teachers of mathematics, and those they must uphold as teachers, which has implications for the apprenticeship model of mathematics.

\subsection{Culture, language and values in mathematics education}

We begin with two cases of cultural clashes, about Hispanic students in Californian universities, and about Pāsifika learners in the New Zealand education system.

Stacy Brown (2018a, b) discusses various excerpts from field notes studying university-level proving activities in a California-based university primarily serving first-generation Hispanic students (often self-identifying instead as Latina/o or Chicana/o). She contrasts the dialects used by the students with the standardised language of research mathematics, especially within proofs:

\begin{abstract}
"Most who have taught university mathematics courses in environments where the majority of students are first generation urban students can readily attest to the varied and at times colorful dialects used. These languages stand in stark contrast to that employed with relative continuity for thousands of years among the practitioners of the discipline of mathematics, especially when writing proofs.” (Brown 2018a, p. 7).
\end{abstract}

She presents multiple classroom artefacts, such as "proof scripts" (student-written scripts for a dialogue discussing key features of a proof), which allow students to explain mathematics in their own dialects. Brown argues that the standard picture of enculturation of students into mathematics and proving activities would see these contributions as failing on several axes. For instance, the students would not have adequately internalised some of the norms and values of proofs discussed above. Their dialect is far away from the standard mathematical patterns of writing, and so the mathematics produced does not conceal the identity of the author, i.e. these pieces of mathematics do not meet the norms of acontextuality individuated by Dawkins and Weber.

Brown claims that while the students have not adapted to the valorised language of mathematics and proofs, they are successfully engaging in advanced mathematical activities of various kinds. Rather than the students being brought into the practices of proof and proving, the teacher has brought the mathematics to a place where the students feel more comfortable. This is the negotiation between the norms of mathematics and the background of the students we mentioned in the introduction. In Sect. 6 we will argue that this negotiation aids in circumventing epistemic injustices.

The language used in mathematics and proofs is also a potential barrier to student participation in the work done by Hunter et al. (2016). They survey the challenges faced in the New Zealand education system by Pāsifika students, where Pāsifika is a broad term for anyone in New Zealand with heritage, ethnic or cultural background connected with the Pacific Islands (see also Coxon et al 2002). Their paper argues that the language and values of Pāsifika learners should be respected and entwined with their mathematics education to improve their performance and to affirm their cultural identities.

With respect to language, Pāsifika students are not just speaking with a dialect, but are often being educated with English not as their first language. This reduces the students' opportunities to learn mathematics:

"Evidence was provided in the studies that show that when teachers and educators drew on the language of Pāsifika students they provided rich opportunities for them to engage in learning and build positive identities. In contrast, when Pāsifika students and their parents were not able to use their home language their opportunities to engage, contribute and feel valued diminished." (Hunter et al. 2016, pp. 202-203).

Hunter et al. argue that learning is significantly improved by allowing the students to communicate and explain mathematics amongst themselves in any language, but this crossusage of multiple languages is at odds with usual English standards of the mathematical vernacular.

In the above two cases standardised English is treated as a default language for mathematics. This may give the impression that this choice of language is an acontextual feature of mathematics writing. However, the choice of language in mathematics has a history which, in the two cases discussed, include colonialist features. These features cannot be divorced from the authors and readers of mathematical writing, which is to say that the language used in this writing is contextual in the sense of Dawkins and Weber.

Students' cultural values are also not accounted for in the apprenticeship model of mathematics teaching. Bills and Hunter (2015) point out that the value of the collective in Pāsifika cultures is starkly opposed to the individualistic style of mathematics:

"The use of streamed groups encouraged competitiveness and placed importance on individual success. An emphasis on the individual in the NZ Numeracy project contrasts directly with Pāsifika notions of the value of collectivism. Within a Pāsifika view the suc- 
cess of group members is measured by the success of the collective as a whole." (Bills and Hunter 2015, p. 110).

While streaming school students is one place this shows up, emphasis on the individual has long been the dominant paradigm in mathematics. It hides the social aspects of mathematics from students, making it seem that mathematics is about the "lone genius" even if this is a misconception of the realities of research mathematics (Martin and Pease 2013; Martin 2015; Lane 2017). Such misconceptions are systematically more damaging to some students than others, as seen in the case where students' cultural values place particular emphasis on cooperative work.

\subsection{Class and mathematics}

The harder challenge faced by some learners compared to others due to a clash of language and values is also familiar from studies on class in mathematics. Work on class in English schooling has been ongoing in education research (Bernstein 1975; Reay 2017), and also specific to mathematics education (Noyes 2003; Jorgensen, Gates and Roper 2014). Jorgensen et al. look at ways in which social capital (Bourdieu 1974, 1983) associated with the learners' class backgrounds sets them up to succeed or fail in mathematics schooling. One mechanism by which this happens is again the language of mathematics:

"Language is an integral part of the social heritage that is brought into school mathematics and becomes reified through various objective structuring practices. Language, in very broad terms, not only conveys particular concepts but also provides a medium through which those concepts are conveyed. It is therefore important to consider not only the concepts that are being considered but also the medium of instruction. The subsequent success (or failure) of students is most frequently interpreted as an innate ability that facilitates, or not, success in coming to learn the disciplinary knowledge within the field of school mathematics." (Jorgensen et al. 2014, pp. 227-228).

The reference to "innate" abilities relates to the myth of the lone genius above. This is potentially dangerous because when advantages stemming from class background are incorrectly viewed as demonstrating innately superior ability, those advantages may falsely appear to be facts of nature. Like the other research above, the effects of social class on mathematics education is not solely through the language used. The values of mathematics that give the appearance of individualistic and competitive success are undermined if this "competition" is rigged from the start. Sadly, this is the experience of many students disadvantaged through social class' interaction with the existing education systems.

\subsection{Culture, class and epistemic injustice}

In the previous two sections we have seen how coming from a certain cultural or class background can be a disadvantage for learners in coming to terms with the mathematical vernacular and values. In the existing mathematics education literature, this has been demonstrated at length, not only in these domains but also with respect to other characteristics of students such as gender, race, disability, chronic pain etc. This can be further compounded through intersectional cases where students fall into multiple of these categories. ${ }^{5}$

Some students require support that accounts for their cultural or class background when learning to engage in mathematical proving activities. From the philosophical perspective, we argue that the apprenticeship model of teaching proving akin to the practices of research mathematicians can, through the various mechanisms discussed, lead to epistemic injustice. The apprenticeship model internalises values and norms of mathematics which elevate the discipline to one of objectivity and acontextuality, but any mathematics that is actually done is done within a context and written using certain types of language. The cases discussed above show that pretending that these are equally accessible to all has systematic harmful and unjust effects. Students who have further to go in terms of accessing the language, values and norms of mathematical practice also have further to go in being enculturated into those practices. This can and does systematically hinder large numbers of potential mathematicians from participating in the epistemic endeavour of mathematical research. We argue in Sect. 6 that the failure to mediate the values and norms of proving with the diverse needs of students can lead to epistemic injustice.

Unlike our previous work on epistemic injustice in mathematics (Rittberg, Tanswell and van Bendegem 2018), where we were considering potential and hypothetical cases of epistemic injustice that could arise in various mathematical practices, the existing mathematics education research we have sampled above demonstrates that epistemic injustices occur in the maths classroom.

"Placing students in multi-racial (or multi-religion or multi-gendered, etc.,) groups in a university class and

\footnotetext{
${ }^{5}$ We note that we have used examples from the literature of mathematics teaching in vastly different setting and for different age groups. We believe that the points we make are generally applicable across these cases, but it is of course an empirical matter how the problems of epistemic injustice manifest differently in different contexts. Our examples should be sufficient to show that the apprenticeship model is in need of refinement to accommodate the ethical dimension of enculturation into mathematical practices.
} 
expecting students to freely collaborate, therefore, is in essence calling on students, if they have not yet already done so, to spontaneously generate the dispositions and perspectives necessary to bridge their recurring experiences of separation.” (Brown 2018a, pp. 11-12).

There are important caveats to this. First, to re-emphasise a point from Sect. 3, the epistemic injustice in the teaching of mathematics described above that we are concerned with is primarily about mathematics as an epistemic institution. Other manifestations of epistemic injustice, such as teachers acting unjustly in their capacities as knowers (a point considered by Jorgensen et al.), may also occur but cannot be treated here.

Second, just because the norms and values of mathematics might have ethical consequences does not necessarily mean that these are not nonetheless the right values and norms for mathematics. An essential part of mathematics as a discipline is the quest for objectivity, and presenting results in a way that reflects this may be most natural. It may be reasonable to expect learners from all backgrounds to come to terms with these norms and values, even if doing so is more difficult for some learners than for others: we might not need to change mathematics entirely just to accommodate those who are not used to ritualised usage of language, for example.

By identifying the injustice that arises here as specifically epistemic, we learn something about how to begin to address it. The classic idea from Fricker would be that we should develop the "epistemic virtue" of epistemic justice, whereby we are motivated towards equitable practices and the fair and equitable treatment of all knowers. We have discussed how the option to simply change the norms and values that run into ethical clashes with the fairness of students' enculturation into mathematics is not so straightforward. The norms and values of mathematics exist for a reason, and represent and reflect central pillars of the epistemic institution of mathematics. To remove or replace these would potentially be akin to giving up on the practice we were attempting to enculturate students into in the first place.

\section{Ethical orders and mathematics education}

The previous section ended with a dilemma regarding the clash of mathematical and ethical values in mathematical practice and mathematics education. We intend to analyse this clash in terms of the notion of ethical orders. In this section we discuss the concept as used by Larvor (2018), developing the idea from Max Weber's lectures Science as a Vocation and Politics as a Vocation, delivered in 1917 and 1919 respectively and collected in (Weber 1948). The central insight of talking in terms of being committed to multiple different ethical orders is in thinking about how they interact and come into conflict with one another. We stand to learn that some dilemmas are genuine dilemmas without a higher theoretical level to appeal to for a solution.

\subsection{Ethical orders}

Larvor develops the notion of an ethical order from Weber's two vocation lectures. Weber's lectures look at the different ethical demands and responsibilities that come with different roles we fulfil in our lives. He argues that the ethics we are subject to depends heavily on the role we are currently occupying:

"But is it true that any ethic of the world could establish commandments of identical content for erotic, business, familial, and official relations; for the relations to one's wife, to the greengrocer, the son, the competitor, the friend, the defendant?" (Weber 1946, pp. 118-9).

The central examples in the two lectures are of the scientist and the politician, two roles that come with very different demands. The role of the scientist involves careful but dispassionate treatment of their subject-matter. She must describe, catalogue, theorise and predict, but does not (in her role as a scientist) make normative judgments about what should follow from the science. The politician must precisely make such normative judgments about how to proceed. As Larvor puts it:

"Part of the point of these two 'vocation' lectures is that the political leader and the scientist are committed to different ethical orders. The leader must offer a moral vision and recommend action; the scientist must not-the scientific ethic forbids it." (Larvor 2018, p. $10)$.

While we are not given an explicit definition of what an ethical order is by Larvor, or indeed Weber, the idea we will take forward from the scientist/politician contrast is that an ethical order is a set of values, virtues, norms, ethical demands and responsibilities associated with some role we might fulfil.

Let us expand on this. Undertaking a role such as scientist, politician, bureaucrat, teacher or mathematician is a skilled activity that comes with an array of values of what is considered important, good or right for someone in that role to do and pursue; and an array of norms of how one should go about realising those values in practice. Furthermore, there are virtues and vices associated with good or bad characteristics someone might have in their role, that will 
in part depend on the role itself. For example, an inspiring politician, teacher and athlete might all be inspiring in very distinct ways, while the virtue of daringness found in the stuntman would be entirely inappropriate in a health and safety inspector. Finally, these different roles place different demands on our behavior, giving us responsibilities particular to our position.

The key insight in discussing ethical orders is that we rarely (if ever) have just one role, and so we are often committed to multiple ethical orders and thereby also to multiple sets of values, norms, and virtues. These multiple orders can conflict, leaving the individual torn between different incompatible"right" courses of action. Larvor argues that this kind of conflict between ethical orders can place a psychological burden on us:

"The existence of multiple ethical orders is existentially strenuous, because ethical orders are not merely social structures or forces external to us. Rather, they are part of our inner structure. If I feel the force of several incompatible ethical orders, then the differences between them are divisions in me." (Larvor, p. 14).

Larvor extracts from Weber that the existence of multiple conflicting ethical orders within us and the existential strain that results may not have a theoretical resolution. It may be that we have multiple incompatible commitments, with no higher-level ethical order to decide which prevails. Weber, with an imaginative flourish, labels this situation as a "polytheism" akin to worshipping multiple deities in a pantheon:

"It is commonplace to observe that something may be true although it is not beautiful and not holy and not good. Indeed it may be true in precisely those aspects. But all these are only the most elementary cases of the struggle that the gods of the various orders and values are engaged in.[...] different gods struggle with one another, now and for all times to come." (Weber 1946, p. 148).

Philosophically, many questions about ethical orders remain: what distinguishes two ethical orders? When are they the same or different? To what extent do I need to be aware of ethical orders that I am committed to? What is the balance of values, norms, virtues and responsibilities? Are these the only components of ethical orders or are there others? We do not propose to answer these questions here, taking the notion of an ethical order to be at least sufficiently clear for thinking about ethical orders of mathematics, which is the main goal of this section.

\subsection{Ethical orders and mathematics education}

We propose that the notion of ethical orders is a useful tool for making a central challenge for mathematics education and the for epistemic injustice to manifest visible.

The challenge is that the classroom is a space in which multiple roles and their associated ethical orders are present and may come into conflict. The process of enculturation into a specific discipline is in part about bringing students into an ethical order, through internalising some of its norms, values and virtues. But students are neither homogeneous nor blank slates; they uphold values and roles and, therefore, ethical orders across their lives. As we showed in the previous sections, the orders learners are being enculturated into are often at odds with the ethical orders these learners are already committed to.

Mathematics, by virtue of its content and abstractness, is a particularly extreme case, as is brought out by Dawkins' and Weber's discussion of its values and associated norms. The clash of ethical orders in this case is between, firstly, the ethical order of research mathematics, which emphasises proofs and their connected norms and values; secondly, the existing and diverse ethical orders that learners are committed to; and the ethical orders of the mathematics teachers in their role as teachers. Values associated with teaching include developing the skills, knowledge and ability of their learners; being fair and encouraging to the students, and avoiding epistemic injustice. But epistemic injustice can arise in teaching mathematics, as we will argue in the next section, when some learners are systematically advantaged because the ethical order of research mathematics echoes familiar norms, values and virtues, while for other students it explicitly or implicitly denigrates their existing ethical orders.

Adopting the framework of ethical orders also helps to identify the many roles that are inhabited in the mathematics classroom, and the array of values, norms and responsibilities these entail. For instance, there are the distinct roles for the student and teacher, which come with very different perspectives, but beyond this they are both engaging with the ethical order of mathematics. Meanwhile, everyone also inhabits a wide range of additional ethical orders from their broader lives (e.g. parent, child, caregiver, citizen, friend) besides those of culture, race, gender, class etc. Many of these are social, and track social power dynamics which are also active in the classroom setting. It is no surprise, then, that there are both internal tensions within both the students and teachers, as they navigate the many ethical orders, but also external tensions as different agents' perspective of different ethical orders come into conflict.

The lesson from Larvor and Weber on ethical orders can be applied here too. In some broad sense, there may be no overarching theoretical solution to the clashing ethical 
orders of research mathematics and students' existing ethical orders, and the epistemic injustice that can arise at this intersection. For the mathematics educator, this may be a genuine dilemma, where the challenges this clash of orders creates will be persistent and difficult.

Nonetheless, this does not need to be a pessimistic conclusion. Rather, the important upshot is to recognise the clash, both internal to the individual and within the classroom, and search for context-dependent practical solutions. In the next section, we return to the particular clash concerning the values and norms of proofs with this perspective.

\section{Ethical orders, acontextual proving and epistemic injustice}

In Sect. 4 we summarised some of the research on the impact of culture and class on the enculturation of learners into mathematical proving practices. We highlighted how belonging to certain social groups can affect the coming to terms with the vernacular of mathematics and its associated values: dialects (Brown), non-native language (Hunter et al.), conflicting values (Hunter et al.), forms of language (Jorgensen et al.). That is, the background of a learner can pose challenges for her in coming to terms with the norms and values of mathematical proving practices. In Sect. 5 we proposed ethical orders as a conceptual tool to engage with this issue. A key insight was that learners are committed to multiple and potentially conflicting ethical orders. These conflicts may only allow for practical but not for theoretical solutions. In this section we tie these insights together to argue that denying learners in the mathematics classroom the possibility to negotiate between the different ethical orders they are committed to can cause epistemic injustices. In particular, we argue that insisting on the acontextuality of proofs when teaching mathematical proving practices closes off spaces in which the diverse ethical orders of learners play out. This, we will argue, can be a source of epistemic injustice in mathematics education. If this argument is correct, then there are ethical reasons not to adhere to a strict reading of the apprenticeship model of teaching mathematics: mathematicians may uphold certain values and their associated norms but teaching these norms and values requires negotiation with pre-existing ethical orders to avoid epistemic injustices.

\subsection{A strong reading of the apprenticeship model}

Dawkins and Weber maintain:

"In line with the view that cultural understanding is generally embedded within cultural know-how, we maintain that proof-instruction -- as an apprenticeship in mathematical practice -- should not shift away from proving practice itself." (Dawkins and Weber 2017, p. 138)

As elaborated in Sect. 3, Dawkins and Weber identify four values of mathematical proving practices and a number of norms intended to uphold these values. They continue.

"We do not advocate explaining to students why they should adopt mathematicians' values, as this would involve recourse to philosophy or some extra-mathematical activity, which philosophers in the naturalistic tradition have abandoned as pointless (e.g. Maddy, 1997)." (ibid.) ${ }^{[6]}$

Instead.

"Having students work with norms initially should provide them with the opportunity to experience the values that the norms are in place to uphold." (ibid.)

That is, the apprenticeship model as put forth by Dawkins and Weber encourages teachers to enforce the norms of mathematical proving practices so that students may come to experience and understand the values of this practice. Our argument is that strict enforcement of the norms of mathematical proving practices in classrooms can be a source of epistemic injustices. To make this argument we focus on one particular value Dawkins and Weber have individuated, the acontextuality of proofs, and the associated norm that mathematical proof be written without reference to author or reader agency.

Before we present our case, it is worth pointing out that Dawkins and Weber did not propose strict enforcement of norms in the classroom. Nonetheless, we challenge the view that if mathematicians adhere to certain norms, then so should learners. Instead we propose that learners should be encouraged to appropriate norms in order to experience the values these norms are intended to uphold and thereby develop a sense for the ethical order of mathematics.

\subsection{Acontextuality of proofs as source of epistemic injustice}

As argued by Dawkins and Weber (2017, p. 129) it is a value of mathematical proving practices that "mathematical knowledge and justification should be independent of (nonmathematical) contexts, including time and author". They identify the norm "mathematical proof is written without reference to author or reader's agency" as intended to uphold this value. In our terminology, these norms and values are part of the ethical order of mathematics.

\footnotetext{
${ }^{6}$ For a "naturalistic" criticism of Maddy (1997), see (Rittberg 2016).
} 
In Sect. 4 we discussed several examples of how belonging to certain social groups can impact one's enculturation into the mathematical vernacular. For example, Zevenbergen (2001) makes the point that working-class children are less attuned to the ritualised use of language, as used in mathematical proofs, than their middle-class classmates. If this is correct, then working-class children are confronted with additional difficulties in satisfying the norms of mathematical proof-writing because they are less attuned to ethical orders that demand ritualised use of language. Similarly, the collective values of the Pāsifika learners Bills and Hunter studied stand in contrast to the lone-genius narrative that acontextual proof-writing reinforces; the ethical order of the Pāsifika culture conflicts with the ethical order of mathematics.

We do not believe that difficulties are by themselves injustices. That some struggle more with certain tasks than others is simply a fact of life. It is in how these difficulties are accounted for that injustices may manifest.

The examples of difficulties we have been discussing in this paper, such as Jorgensen et al. or Bills and Hunter's work, manifest in the reading and writing of mathematical proof. The reading and writing of mathematical proof belong, with Dawkins and Weber, to the context of mathematical proof. That is, (some of) the difficulties learners face with mathematical proof play out in the context of mathematical proof.

There is thus a tension between the demand of the ethical order of mathematics that proofs be independent of their context and the classroom reality that certain difficulties learners face when being enculturated into mathematical proving practices manifest in the context of proof.

To demand the acontextuality of proof in the classroom is to overlook a space in which difficulties with the ethical order of mathematics arise. This turns these difficulties into disadvantages. That is, by strictly enforcing the ethical order of mathematics in the classroom one risks disadvantaging some learners in their participation in an epistemic practice. The ethical order of mathematics can thus be a source of epistemic injustice: strict enforcement in the classroom can lead to disadvantages for some.

What we learn from works such as Brown's or Bills and Hunter's (cf. Sect. 4) is that the ethical order of mathematics is negotiable in the classroom in a way that counteracts such injustices. These scholars broke the norm that mathematical proof should be acontextual to engage with the difficulties the learners in their classrooms faced. For example, Brown allowed breaking with the mathematical vernacular of mathematical proof-writing, which made proofs more idiosyncratic and thus contextual in Dawkins' and Weber's sense. By allowing mathematical proofs to be contextual in the classroom these scholars enable a space for negotiating the difficulties that arise from the cultural and social backgrounds of learners. This avoids turning difficulties into epistemically unjust disadvantages. Mathematics can and should meet the learners halfway.

Indeed, Sørensen, Danielsen, and Andersen (2019) provide some empirical evidence that allowing the context of proofs a space in the mathematics classroom may be beneficial to the enculturation process into mathematical proving practices beyond the negotiation of disadvantages. They propose to teach reader engagement as an aspect of proof. By this they mean that learners get a say in what counts as a proof for them. The authors argue that.

"[...] this provides a reason for [the learners] to actively engage with the proof, identify steps they cannot follow, and ask the teacher to add details or do so themselves." (Sørensen et al. 2019, p. 836) "[...] through the teaching of reader engagement as an aspect of proofs, the student may come to see the proofs she encounters in the classroom as 'proofs for me' which may in turn empower and motivate her to take on a more active role in engaging with the proofs." (Sørensen et al. 2019, p. 842)

To corroborate their insights, the authors encouraged a Danish secondary school teacher to teach reader engagement. The, by now unsurprising, upshot was that.

"The teacher had acquired nuanced insights into the difficulties the students faced, and he could draw on a concrete example to address these." (ibid.)

In this section we have argued that enforcing the ethical order of mathematics in the classroom can hide difficulties learners face in epistemically unjust ways. Epistemically just teaching, we suggested, negotiates between the different ethical orders present in the classroom, thereby accounting for cultural, social, and other challenges learners need to overcome to be successfully enculturated into mathematics.

\section{Conclusions}

The apprenticeship model of mathematics education suggests, in the terminology of this paper, that learners should be enculturated into the ethical order of mathematics. We agree that at the end of successful teaching learners are enculturated into the (relevant parts of the) ethical order of mathematics. Our reservations about the apprenticeship model concern the process of teaching. We have shown that the ethical orders learners are committed to can stand in conflict with the ethical order of mathematics. This conflict is experienced by the learners as difficulties in coming to terms with the ethical order of mathematics. Our argument is that 
enforcing the ethical order of mathematics during teaching transforms these difficulties into systematic disadvantages. It is in this transformation that epistemic injustice manifests. We have thus given ethical reasons why classroom mathematics ought, on occasion, to break with the ethical order of research mathematics.

Our argument leads to the thought that the apprenticeship model is in need of refinement. Our proposal is that this refinement is to include the ethical-epistemic dimension of enculturation into mathematical practices. We believe this is best seen through the framework of ethical orders, and the negotiation of tensions between such ethical orders for teachers and students.

We have suggested that there needs to be negotiation between the ethical orders learners are committed to and the ethical order of mathematics in the mathematics classroom. That this is possible is shown by the ample examples of success stories in the mathematics education literature (cf. Sect. 4). Proponents of the apprenticeship model ought therefore to be interested in and inquire into how this negotiation can be most fruitfully implemented in the classroom. The insight we take from Larvor (2018) is that when ethical orders come into conflict there may be no theory which could provide general solutions to overcome this conflict. We may need what Larvor has called "trickery": pragmatic solutions tailored to the given situation. This is what Hunter, Brown, and the other scholars discussed in Sect. 4 did. And it may be an important area of research for the development of the apprenticeship model.

Contemporary education theory understands that children are not little adults and that treating them as such is unjust. In this paper we have argued that mathematics learners are not little research mathematicians and demanding that they operate in the same ethical order is a source of epistemic injustice.

Acknowledgements We would like to thank Brendan Larvor for invaluable help with this paper. We also thank Paola Iannone and Colin Foster for comments on earlier drafts. Many thanks to the anonymous referees, guest editors and editor for ZDM who provided extensive and helpful feedback. Research for this paper by the second author has been funded by the Research Foundation - Flanders (FWO), project G056716N, and the Centre for Mathematical Cognition at Loughborough University.

Open Access This article is licensed under a Creative Commons Attribution 4.0 International License, which permits use, sharing, adaptation, distribution and reproduction in any medium or format, as long as you give appropriate credit to the original author(s) and the source, provide a link to the Creative Commons licence, and indicate if changes were made. The images or other third party material in this article are included in the article's Creative Commons licence, unless indicated otherwise in a credit line to the material. If material is not included in the article's Creative Commons licence and your intended use is not permitted by statutory regulation or exceeds the permitted use, you will need to obtain permission directly from the copyright holder. To view a copy of this licence, visit http://creativecommons.org/licenses/by/4.0/.

\section{References}

Battey, D., \& Leyva, L. A. (2016). A framework for understanding whiteness in mathematics education. Journal of Urban Mathematics Education, 9, 49-80.

Bernstein, B. (1975). Class and pedagogies: Visible and invisible. Educational Studies, 1, 23-41.

Bills, T., Hunter, R. (2015). The Role of Cultural Capital in Creating Equity for Pāsifika Learners in Mathematics. In Marshman, M., Geiger, V., and Bennison A. (eds.), Mathematics education in the margins (Proceedings of the 38th annual conference of the Mathematics Education Research Group of Australasia). Sunshine Coast: MERGA, 109-116.

Bourdieu, P. (1974). The School as a Conservative Force: Scholastic and Cultural Inequalities. In Egglestone, J. (ed.), Contemporary Research in the Sociology of Education. London: Methuen.

Bourdieu, P. (1983). The forms of capital. In J. G. Richardson (Ed.), Handbook of theory and research for the sociology of education (pp. 241-258). New York: Greenwood Press.

Brown S (2018a). E-IBL: An exploration of theoretical relationships between equity-oriented instruction and inquiry-based learning. In Weinberg, A., Rasmussen, C., Rabin, J., Wawro, M., and Brown, S. (eds.), Proceedings of the 21st Annual Conference on Research in Undergraduate Mathematics Education. 1-15.

Brown, S. (2018b). Leveraging the perceptual ambiguity of proof scripts to witness students' identities. In Weinberg, A., Rasmussen, C., Rabin, J., Wawro, M., and Brown, S. (eds.), Proceedings of the 21st Annual Conference on Research in Undergraduate Mathematics Education. 1407-1413.

Carel, H., \& Kidd, I. J. (2014). Epistemic injustice in healthcare: A philosophical analysis. Medicine, Health Care and Philosophy, 17(4), 529-540.

Coxon, E., Anae, M., Mara, D., Wendt-Samu, T., \& Finau, C. (2002). Literature review on Pacific education issues. Wellington: Ministry of Education.

Davis, P., \& Hersh, R. (1981). The mathematical experience. Boston: Houghton-Mifflin.

Dawkins, P. C., \& Weber, K. (2017). Values and norms of proof for mathematicians and students. Educational Studies in Mathematics, 95, 123-142.

Easwaran, K. (2009). Probabilistic Proofs and Transferability. Philosophia Mathematica (III), 17, 341-362.

Fricker, M. (2007). Epistemic injustice: power and the ethics of knowing. Oxford: Oxford University Press.

Hookway, C. (2010). Some varieties of epistemic injustice: Reflections on Fricker. Episteme, 7(2), 151-163.

Hunter, J., Hunter, R., Bills, T., Cheung, I., Hannant, B., Kritesh, K., et al. (2016). Developing equity for pāsifika learners within a New Zealand context: Attending to culture and values, New Zealand. Journal of Education Studies, 51, 197-209.

Jorgensen, R., Gates, P., \& Roper, V. (2014). Structural exclusion through school mathematics: Using bourdieu to understand mathematics as a social practice. Educational Studies in Mathematics, 87, 221-239.

Kelly, S. (2009). The black-white gap in mathematics course taking. Sociology of Education, 82(1), 47-69.

Kidd, I. J., Medina, J., \& Pohlhaus, G. (Eds.). (2017). The routledge handbook on epistemic injustice. London: Routledge.

Kneebone, G. T. (1957). The philosophical basis of mathematical rigour. The Philosophical Quarterly, 7, 204-223.

Kotzee, B. (2017). Education and Epistemic Injustice. In Kidd et al. (eds.) The Routledge Handbook on Epistemic Injustice. London: Routledge, 324-335.

Lakatos, I. (1976). Proofs and refutation. Cambridge: Cambridge University Press. 
Lane, L. (2017). Bridge between worlds: relating position and disposition in the mathematical field. $\mathrm{PhD}$ thesis: University of Edinburgh.

Larvor, B. (2001). What is dialectical philosophy of mathematics? Philosophia Mathematica (III), 9, 212-229.

Larvor, B. (2018). Weber and Coyote: polytheism as a practical attitude. Sophia: International Journal of Philosophy and Traditions. https://doi.org/10.1007/s11841-018-0641-1

Martin, U. (2015). Stumbling Around in the Dark: Lessons from Everyday Mathematics. In Felty, A.P. and Middeldorp, A. (eds.). Proceedings of CADE (Conference on Automatic Deduction) 25. Lecture Notes in Artificial Intelligence 9195. Cham: Springer International, 29-51.

Martin, U. and Pease, A. (2013). Mathematical Practice, Crowdsourcing and Social Machines. International Conference on Intelligent Computer Mathematics. Berlin: Springer, 98-119.

Medina, J. (2013). The epistemology of resistance: gender and racial oppression, epistemic injustice, and resistant imaginations. Oxford: Oxford University Press.

Noyes, A. (2003). School transfer and social relocation. International Studies in Sociology of Education, 13, 261-280.

Pimm, D. (1987). Speaking mathematically. London: Routledge \& Kegan Paul.

Pohlhaus, G. (2017). Varieties of Epistemic Injustice. In Kidd et al. (eds.) The Routledge Handbook on Epistemic Injustice. London: Routledge, 13-26.

Reay, D. (2017). Miseducation: inequality, education and the working classes. Bristol: Policy Press.

Rittberg, C. J. (2016). Methods, Goals, and Metaphysics in Contemporary Set Theory. $\mathrm{PhD}$ thesis: Hertfordshire University. https ://uhra.herts.ac.uk/handle/2299/17218. Accessed 13 June 2020

Rittberg, C. J., Tanswell, F. S., \& Van Bendegem, J. P. (2018). Epistemic injustice in mathematics. Synthese. https://doi.org/10.1007/ s11229-018-01981-1.
Seceda, W. G., Fennema, E., \& Adajian, L. B. (1995). New Directions for equity in mathematics education. Cambridge: Cambridge University Press.

Sørensen, H. K., Danielsen, K., \& Andersen, L. E. (2019). Teaching reader engagement as an aspect of proof. ZDM, 51, 835-844.

Tanswell, F. (2016). Proof, rigour and informality: A virtue account of mathematical knowledge. PhD Thesis: University of St. Andrews. https://research-repository.st-andrews.ac.uk/handle/10023/10249. Accessed 13 June 2020

Tanswell, F. (2018). Conceptual engineering for mathematical concepts. Inquiry, 61, 881-913.

Treisman, U. (1992). Studying students studying calculus: A look at the lives of minority mathematics students in college. The College Mathematics Journal, 23(5), 362-372.

Wagner, R. (2010). Who speaks mathematics: a semiotic case study. Philosophical Perspectives on Mathematical Practice, 12, 205-234.

Weber, M. (1917). Science as a vocation. Weber, 1948, 129-156.

Weber, M. (1919). Politics as a vocation. Weber, 1948, 77-128.

Weber, M. (1948). Max Weber: essays in sociology. Translated and with an introduction by H.H. Gerth and C. Wright Mills. Abingdon: Routledge.

Wood, M. B. (2013). Mathematical micro-identities: moment-tomoment positioning and learning in a fourth-grade classroom. Journal for Research in Mathematics Education, 44, 775-808.

Zevenbergen, R. (2001). Language, social class and underachievement in school mathematics. In P. Gates (Ed.), Issues in mathematics teaching (pp. 38-50). London: Routledge Falmer.

Publisher's Note Springer Nature remains neutral with regard to jurisdictional claims in published maps and institutional affiliations. 